\title{
La representación fotográfica del círculo de la violencia de género en Salta, Argentina
}

The photographic representation of the circle of the gender violence, in Salta, Argentina

\section{Diana Deharbe}

Universidad Nacional de Entre Ríos, Paraná, Argentina.

dianadeharbe88agmail.com

https://orcid.org/0000-0003-1061-7322

\section{Resumen}

Este artículo reflexiona sobre los modos visuales en los cuales se representa la violencia de género a través del análisis semio-pragmático del ensayo fotográfico del fotoperiodista argentino Gastón Iñiguez titulado, Siete Vidas. Sobrevivir a la violencia machista (2018), que retrata las múltiples facetas y secuelas de la violencia de género a través del relato de siete mujeres. Metodológicamente, se analizaron las imágenes atendiendo a las representaciones visuales actuantes en las imágenes, los códigos de decodificación-codificación, la relación entre el código lingüístico y el visual, y un análisis a nivel formal y compositivo de las imágenes. El análisis también incluye una entrevista en profundidad con el autor. El principal resultado que destacamos es que las representaciones visuales que componen el ensayo funcionan como metáforas del denominado círculo de la violencia de género que problematizan la temática que representan.

Palabrasclave: violencia de género; representación; fotografía; ensayo visual.

\begin{abstract}
This article addresses the visual ways in which gender violence is represented through the semi-pragmatic analysis of the photo essay by the photojournalist, Gastón Iñiguez titled, Siete Vidas. Sobreviviendo a la violencia machista (2018), which portrays the multiple facets and consequences of gender violence through the story of seven women. Methodologically, the images were analyzed regarding the visual representations shaping the images, the decoding-coding clues, the relationship between the linguistic and the visual code and an analysis of both formal and compositional dimensions of the images. The analysis also included an in-depth interview with the author. One of the main results highlights that the visual representations that make up the essay function as metaphors of the known cycle of gender violence and, building up from that, allow us to critically address the issue they represent.
\end{abstract}

Keywords: gender violence; representation; photography; visual essay. 


\section{Introducción}

Este artículo reflexiona sobre los modos visuales en los cuales se representa la violencia contra las mujeres a través del análisis semio-pragmático del ensayo visual del fotógrafo Gastón Iñiguez', Siete Vidas. Sobrevivir a la violencia machista. Las fotografías se nutren de los relatos de siete mujeres sobrevivientes de violencia sexista publicadas a finales del año 2016 en el semanario Cuarto Poder de la ciudad de Salta, Argentina, y que sirvieron de gatillante.

Desde sus orígenes, la fotografía ha demostrado ser un dispositivo de lo real en tanto construye y cuestiona instantes visuales de verdad. Toda imagen construye un punto de vista que se sustenta en "políticas de la mirada" (Reguillo, 2008) que implican una posición ética y política sobre aquello que representan. La fotografía,

al proponer un lugar del mirar, admite una ética, pues pone el acento en una forma de ver lo otro y el otro, de construir una lógica del sentido, de estimar lo visible, lo ausente y lo presente que no es otra cosa que una preocupación por el otro y por sí mismo (Olayo \& Herrera, 2014: 95)

¿Cuáles son los modos visuales mediante los cuales se representa la violencia de género en el discurso fotográfico? Esta pregunta se la hacemos a un artefacto cultural específico, el fotolibro, Siete Vidas. En tanto objeto estético, las imágenes allí contenidas podrían resultar en modos no estereotipados de representar los efectos que la violencia contra la mujer genera en la subjetividad femenina y, por consiguiente, contribuiría al debate sobre la producción y circulación de imágenes en torno a la temática en espacios mediáticos.

En los medios de comunicación, las imágenes de la violencia se construyen en torno al miedo como única visibilidad posible (Sontag, 2004). Así, cuerpos y víctimas aparecen retratadas anónimamente para ser observadas como una consecuencia aleccionadora, "la imagen del cuerpo violentado supone una invisibilización de los actos violentos y sus implicancias" (Olayo \& Herrera, 2014, p.96). Un corpus robusto de investigación ha documentado ampliamente los modos de construcción de los relatos noticiosos sobre la violencia contra las mujeres: cómo, por qué y bajo qué modalidades se retratan los hechos violentos bajo enfoques de espectacularización de la violencia hasta su máxima teatralización. Una lectura semio-pragmática de las imágenes sugiere que el uso de los primeros planos que acentúan y replican el terror coloca al espectador ante lo incomprensible, lo impensable: la perplejidad ante lo (in)creíble obtura la posibilidad de ver más allá de lo que ellas muestran que usualmente exacerban el poder del victimario y su potencia de muerte, despolitizando el acto violento (Olayo \& Herrera, 2014).

Las imágenes de la violencia contra las mujeres nos colocan ante una paradoja: las fotografías son, simultáneamente, verdad y oscuridad, inmediatez y complejidad de algo que fue arrebatado al tiempo y a la muerte misma (Didi-Huberman, 2004). En esta lucha simbólica por el punto de vista, a las víctimas no les queda más que el silencio no sólo de sus relatos sino también de la ausencia de representación. La muerte es doble.

Si las imágenes de la violencia contra las mujeres pertenecen a esa "estética negativa" - lo (in)visible, lo (in)representable, lo (in)figurable, lo (in)imaginable- de la que habla Didi-Huberman (2004) y, en vez de ayudarnos a comprender visualmente su complejidad, se convierten en "objetos de inatención" que, por hipertrofia o vacío, nos decepcionan; es obligación perseverar en el pensamiento justo allí donde pareciera fracasar.

La perspectiva semio-pragmática, las herramientas teóricas de Barthes $(1986$; 1989; 1994) para discutir la relación entre los códigos actuantes en las imágenes, la semiótica de la imagen para un análisis formal de las fotografías (Aumont, 1992; Joly, 1994), las políticas de la mirada (Reguillo, 2008) en tanto representación de las violencias (Imbert, 1992) y el pensamiento histórico-filosófico ligado a la historia y crítica del arte de Didi-Huberman (2014), alimentan el enfoque para el análisis. Por último, se analizan las representaciones sociales (Arancibia \& Cebrelli, 2005) que se ponen en juego en las fotografías analizadas.

Nuestra estrategia metodológica incluyó, en primer lugar, una observación y lectura de las 56 imágenes en blanco y negro que componen el fotolibro, decodificando los tópicos unificadores que, a nivel iconográfico, se reiteran en las fotografías allí seleccionadas. Se agruparon las imágenes según los 
elementos narrativos que empleaban para generar significado: cadenas, candados y sogas, marcas de manos, rejas, alambrados y/o tablas de madera. También se tuvo en cuenta qué tipo de emoción intentaba representar la imagen.

Luego, identificados dichos tópicos, observamos cómo dialogan con el texto escrito, es decir, cuáles eran los procedimientos específicos de denotación y connotación que, apoyados en cuestiones formales y compositivas, tenían lugar y cuáles eran los grados de equivalencia, colaboración y/o (in) dependencia que había entre ambas materialidades significantes. En un tercer momento, se identificaron las representaciones sociales allí presentes observando cómo dichas fotografías se servían de figuras retóricas para abordar la violencia de género.

Por último, se realizó una entrevista al fotógrafo/ autor del trabajo a fin de establecer un diálogo entre las anticipaciones y motivaciones del proyecto y los resultados hallados mediante el análisis. La misma consistió en dos encuentros presenciales en los cuales, en un primer momento, se indagó respecto a la trayectoria del fotógrafo, sus inclinaciones estéticas, sus objetivos artísticos-políticos respecto al ensayo y las premisas que guiaron la creación visual. Luego, se le solicitó al artista que recorriera las imágenes e intentara agruparlas teniendo en cuenta el relato que deseaba contar respecto a las violencias sexistas. Estas apreciaciones son las que entran en diálogo con el análisis formal para generar los resultados presentados en este artículo.

\section{Motivaciones y expectativas en torno al proyecto fotográfico}

Siete Vidas. Sobrevivir a la violencia machista es un fotolibro, un ensayo visual que representa fotográficamente la historia de siete mujeres sobrevivientes de violencia de género. La propuesta fue una de las ganadoras del Fondo Ciudadano para el Desarrollo Cultural del año 2017, política pública cuya finalidad es financiar proyectos que visibilicen iniciativas culturales y turísticas con impacto social.

El fotolibro se estructura en torno a los relatos de siete mujeres salteñas sobrevivientes de violencia de género, cuyas historias aparecieron por prime- ra vez como comentarios en Facebook vertidos al hilo de la publicación de una nota del semanario salteño Cuarto Poder². Macarena, Luisina, Magalí, Rocío, Fernanda, Jimena y Guadalupe exploran en sus relatos las múltiples facetas de la violencia machista que se ejerce sobre los cuerpos femeninos y disidentes. Uno de los relatos del fotolibro explora la especificidad que adquiere la violencia cuando se ejerce sobre un cuerpo trans, cuestión comúnmente ausente en el abordaje mediático de la problemática (Deharbe \& Zurita, 2019). Rosalyn Ruíz ${ }^{3}$ es la modelo que personifica trazos de las siete historias de resiliencia.

La provincia de Salta, Argentina, se encuentra entre los primeros lugares de muertes por femicidios, crímenes por medios sexuales, acoso y abuso a nivel nacional. Ante este panorama, Iñiguez comenzó a preguntarse cómo podían convivir en los medios imágenes con visibilidades opuestas: las de la liberación y el empoderamiento y su contracara, las aleccionadoras que representaban al extremo la crueldad del mensaje violento que el machismo imprime en los cuerpos femeninos, "las imágenes que ilustraban las notas mostraban cuerpos o rostros abatidos y los textos transmitían un mensaje aleccionador" (Iñiguez, 2018, p.12). La vulnerabilidad también se mide en la visibilidad (Reguillo, 2008) que los medios de comunicación vehiculizan cuando legitiman ciertos modelos visuales de ver/ mirar/pensar lo social (Guasch, 2003; Berger, 1972).

Un fotolibro es un conjunto de imágenes hilvanadas de forma coherente que construyen un relato visual sobre una temática en particular (Vásquez Escalona, 2011). En tanto artefacto cultural, es un producto gráfico cuyo objetivo es colocar en circulación la narración visual elaborada por el fotógrafo (Reyero, 2015). Durante su elaboración, se utilizan diferentes herramientas para ir en búsqueda de la otredad que se intenta representar poniendo en diálogo la propia mirada del artista. Iñiguez afirma que el ensayo Siete Vidas formó parte de un cuestionamiento personal y un intento de repensar sus propias prácticas en relación a la violencia. Habla, dice, de "un proceso de búsqueda interna al momento de enfrentar y re interpretar los relatos originales" "Iñiguez, 2018, p.12).

Barrios (2018) sostiene que el análisis de las fotografías en tanto texto polisémico debe realizarse poniendo en diálogo aquellos otros "textos" que de 
manera intra y extra discursiva complejizan su lectura. De este modo, es analíticamente pertinente considerar la trayectoria del fotógrafo, el lugar desde el cual se posiciona para construir visualmente su producción, así como sus referencias y criterios estéticos. Reyero (2015), leyendo a Ricoeur, nos advierte que "el problema de la comprensión no se resuelve mediante el simple retorno a la intención del autor" (2015, p.11); la lectura de la imagen requiere de un despliegue teórico-metodológico a fin de explicitar las posibles preguntas y respuestas que despierta el observarlas analíticamente.

Siete Vidas es un ensayo cohesionado por la temática (Vásquez Escalona, 2011) en torno a la violencia de género. Todo ensayo visual comienza con una premisa o idea que actúa de faro en la búsqueda por intuición (Vásquez-Escalona, 2011, p. 308), en este sentido, Iñiguez sostiene que, "partimos de la idea de mostrar el cuerpo pero no de una forma obvia y buscando evitar la imagen trillada de la mujer, en este caso, abatida y rota" (Iñiguez, comunicación personal, abril 2019).

En él, el artista mixtura, por un lado, influencias ancladas en el modelo de fotografía documental que se aprecia claramente en la elección estética blanco-negro y, por el otro lado, estilos del modo realista que,

concierne al mundo de los hechos; en este modelo la realidad empírica influye en la ciencia con una tendencia positivista o empírica; y su función es analógica, la de una verdadera representación que sustituye a la realidad - 'así es como es'-. Finalmente, está el modo documental, perteneciente al mundo de la acción, a la creencia de que las fotografías pueden tener un efecto práctico en la vida diaria o, más dramáticamente, pueden inspirar la acción para cambiar el mundo presente a mejor (Sáenz, 2015, p. 247).

\section{Decisiones estéticas y políticas en torno a las imágenes}

Siguiendo a Aumont (1992) y Joly (2012), nos detendremos en el análisis de cuestiones compositivas de las fotografías describiendo el papel del dispositivo y atendiendo a los efectos ideológicos y de poder que actúan no solo a nivel de los conteni- dos, sino también en lo formal y en las elecciones técnicas como connotadores ideológicos. Luego, siguiendo a Barthes (1986) atenderemos a la relación entre las imágenes y el texto indagando en el uso y función de los epígrafes o pie de fotos.

Con respecto a las cuestiones de composición, la mayoría de las fotografías están centradas; eso quiere decir que los elementos sobre los que el fotógrafo desea que el espectador detenga su mirada están ubicados sobre los cuatro puntos áureos, aprovechando la ley de los tercios. El fotógrafo utiliza la tensión visual generada por la intersección de las líneas imaginarias para destacar con reiterado entusiasmo el papel de las manos y explorar diferentes estados de ánimo a través de los gestos de miedo, dolor, temor, angustia, tristeza y soledad que la modelo va explorando y experimentando a medida que transita los relatos de las siete mujeres.

Si consideramos que el plano y el encuadre no sólo hablan del recorte, de esa selección y fragmentación consciente-inconsciente que opera el fotógrafo de origen épocal, sino que, también, nos habla de la distancia simbólica que se construye con lo representado, el uso de planos medios y primeros planos tiene como efecto indirecto en el espectador, acortar las distancias, simular la inmediatez del tacto y apelar a la expresividad, la proximidad y la intimidad (Aumont, 1992). Estos elementos son consistentes con los objetivos que se había propuesto el fotógrafo de transmitir empatía.

Sobre las elecciones estéticas, Iñiguez afirma que, en primer lugar, el uso del registro monocromático fue una decisión atada al presupuesto y los costos de edición del fotolibro en su versión impresa. Segundo, el autor justifica la elección del blanconegro pues permitía,

utilizar un contraste alto para marcar la separación de la figura en primer plano del fondo y para conseguir un efecto pictórico en las texturas. Por último, el foco diferencial y los planos fuera de foco se utilizaron para potenciar el relato en algunas fotografías (Iñiguez, comunicación personal, 2019).

Es clave reflexionar cómo se conjugan los sentidos que dicha elección estética implica con la pretensión primera del autor respecto a la recepción de su obra. Siguiendo a Newhall (2002), el uso del blanco-negro es propio del estilo de la fotografía 
documental que tuvo su auge a inicios del siglo XX, en particular durante el período de entreguerras, y que luego fue absorbido por la tradición del fotoperiodismo. Lo que en principio respondía a las limitaciones técnicas propias del dispositivo, con el surgimiento de la fotografía en color, el uso del blanco y negro se asoció a la objetividad generando efectos de nostalgia y/o distancia con lo retratado mientras que, por el contrario, el uso del color era un claro indicador de la intervención de la subjetividad del autor y una marca de un producto estético más cercano al arte. Como técnica de composición visual su objetivo es que el espectador focalice su atención en la forma y en la relación de lo retratado más que en el color de los objetos (Newhall, 2002).

En este sentido, y atendiendo a lo señalado por el fotógrafo, su adscripción a la tradición documentalista es evidente y se denota en sus elecciones estéticas. Ahora bien, son justamente estas elecciones las que, en algún punto, comprometen su interés explícito en retratar la violencia de género desde la proximidad y la empatía. Esta operación estética de connotación (Barthes, 1982) opera delimitando límites de representación visual para las violencias de género y reproduciendo aquellas asimetrías que pretende desandar. Así, el alto contraste de las imágenes acentúa toda una gama de producciones iconográficas que circulan culturalmente respecto a la temática que la reducen solo a su expresión física. El uso reiterativo de cadenas y candados produce una exotización del acto violento que obtura una reflexión integral, naturalizando y legitimando el ejercicio de violencia simbólica que implica la reproducción de tales imágenes en los medios de comunicación cuya consideración se encuentra ausente.

De igual manera, la elección estética invisibiliza, por la ausencia premeditada del color, el interés del fotógrafo de retratar rasgos femeninos de belleza no hegemónica mediante la elección de una modelo no blanca. Si bien Iñiguez admite que la escogió dado la versatilidad que él observaba en su porte, característica que le permitiría visibilizar ciertas variables interseccionales como la raza y la identidad de género, abordando la problemática de la violencia de manera transversal, dicho objetivo se desvanece en las poses adoptadas y las metáforas visuales adoptadas.

Sin embargo, debe destacarse la pretensión del fotógrafo de intentar distanciarse de los lugares ha- bituales que pautan las políticas de la mirada para la representación de las violencias por motivos de género, aunque el producto final no llegue a concretar totalmente dicha pretensión. Si todo marco epistemológico es político e ideológico, las imágenes estrechan el diálogo con el pensamiento asociado al giro decolonial, explicitando la necesidad de explorar y visibilizar los lazos profundos entre violencia e interseccionalidad (Crenshaw, 2012). Como señala Berlanga-Gayón (2014), las violencias contra las mujeres y el feminicidio en América Latina tienen color y se expresan en la imágenes de mujeres racializadas, ya que "el valor que se les asigna a los cuerpos femeninos racializados y que se traduce en circunstancias materiales concretas: pobreza, explotación y marginación. La precariedad, sin embargo, también se puede traducir en silencio o falta de visibilidad" (2014, p. 43). Que el fotógrafo enuncie la necesidad de mostrar un cuerpo no hegemónico da cuenta de la toma de conocimiento de "la violencia contra las mujeres en América Latina está ligada al menosprecio por la raza" (Berlanga-Gayón, 2014, p.44) y que hay una jerarquía que regula el valor de las vidas donde, claramente y al decir de Butler (2010), las vidas de las mujeres de color no merecen ser lloradas: "hay cuerpos que valen más y hay cuerpos que valen menos" (Proyecto NUM, 2017).

Un párrafo aparte merece la elección del escenario elegido para realización de la producción fotográfica: el río la Caldera4. Según el fotógrafo, la elección de una locación natural para las tomas respondió al intento por visibilizar el hecho de que, cuando las mujeres son asesinadas, son justamente los ríos, basurales o descampados donde los femicidas descartan los cuerpos de sus víctimas. En Salta, los cuerpos de cuatro de las veinticuatro mujeres asesinadas en 2017 fueron encontrados sobre la orilla de los ríos o en cercanías de cursos de agua ${ }^{5}$. Como sostiene Segato (2016), los cuerpos femeninos históricamente han sido un territorio de guerra, disputa y apropiación y que el patriarcado se sostiene en la producción de una violencia de orden simbólica (Bourdieu, 2000) que garantiza el sostenimiento y la reproducción del sistema de desigualdades sexogenéricas, donde el cuerpo de las mujeres es parte de esa "basura simbólica" que produce continuamente el poder (Silva-Santisteban, 2008).

El ensayo visual fue un proceso colaborativo de creación del cual participaron las propias mujeres 
sobrevivientes, incluida la mujer retratada, Rosalyn Ruíz. Dicha opción, al decir de Iñiguez, es "una toma de posición política sobre el tema y una forma de militancia (...) este libro fue un proceso de búsqueda interna (...) vino por comenzar a cuestionarme y cuestionar (...) pensar y re-pensar mis propias acciones" (Iñiguez, comunicación personal, abril 2019). De todos modos, más allá de las intenciones enunciadas, no debe perderse de vista la asimetría de poder siempre enredada en la relación entre quién obtura y el objeto/sujeta representado/a.

La utilización de la fotografía como medio terapéutico no es reciente. De hecho, hay trabajos que mencionan las ventajas de la fototerapia en la intervención terapéutica con mujeres sobrevivientes de violencia (Lockett, 2014; López-Ruíz \& LópezMartínez, 2019]. Entendida como un proceso por el cual y mediante la creación de fotografías, especialmente autorretratos, se trabaja sobre la comprensión y reflexión de situaciones traumáticas para generar campos positivos en los pensamientos y comportamientos de las personas participantes. La fototerapia crea potentes metáforas visuales que, para mujeres sobrevivientes a la violencia de género, representa una oportunidad de transitar el trauma y re-significar la experiencia vivida (Lockett, 2014). En el caso de Siete Vidas, Rosalyn Ruíz realiza un ejercicio de exteriorización y personificación de la violencia de los relatos para construir metáforas visuales de un proceso de aceptación y sanación a través del cual, tanto ella como quién/es se sienten interpelados/as, punzados por las imágenes, disputan el sentido en torno al trauma de la violencia de género.

\section{El círculo de la violencia y su representación en imágenes}

Siete Vidas. Sobrevivir a la violencia machista es una alegoría dedicada a la violencia de género. De la variedad de imágenes que componen el ensayo, algunas fotografías funcionan como metáforas de lo que se conoce como el círculo de la violencia: silencio, prisión, sometimiento, soledad, tristeza, aislamiento, invisibilidad. Recurriendo a Barthes (1989), identificamos los códigos culturales hegemónicos actuantes en las representaciones visuales que responden al studium, ya que toda imagen denota/ connota significaciones. Es por ello que los elementos denotados y que se reafirman en la presencia de los epígrafes son imágenes altamente fetichizadas, donde elementos como cadenas, candados, alambres, tablas de maderas simulando ser rejas representan aquel estado de encierro, de privación de la libertad no sólo física sino también emocional

(Fotografía 3) que sutura en la tristeza o congoja que transmite la emocionalidad de los gestos de Rosalyn (Fotografía 1 y 2).

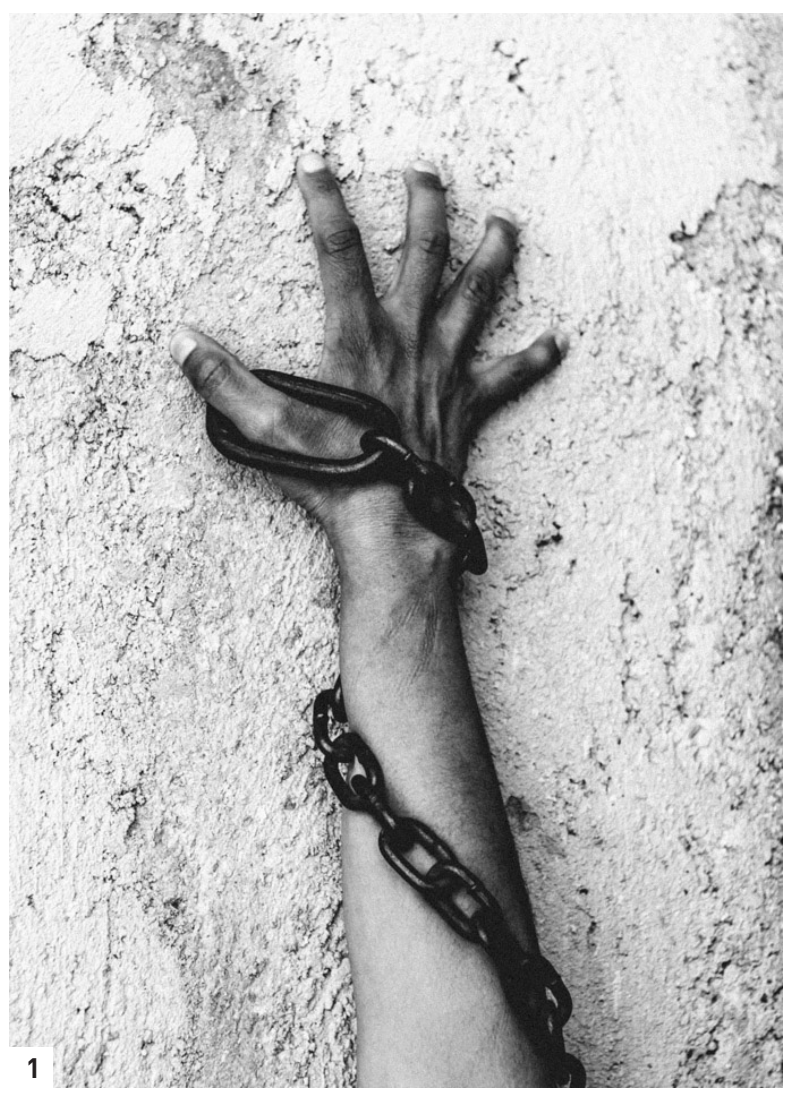

Fotografía 1. Sin título

Fuente: IÑIGUEZ, G. Siete Vidas. Sobrevivir a la violencia machista. Salta: El Pentaprisma, 2018, p. 56.

Identificamos tópicos unificadores capaces de organizar las fotografías. Estos fueron construidos en el proceso de análisis mediante una observación detenida de las escenas representadas y del diálogo que entablan con los pies de fotos que, en la mayoría de los casos, funcionan como relevos de información no contenida en las imágenes y que apuntan a reponer el contexto y la temática abordada por el ensayo. Luego, atendiendo al registro y prestando atención a los códigos estéticos operantes en las 


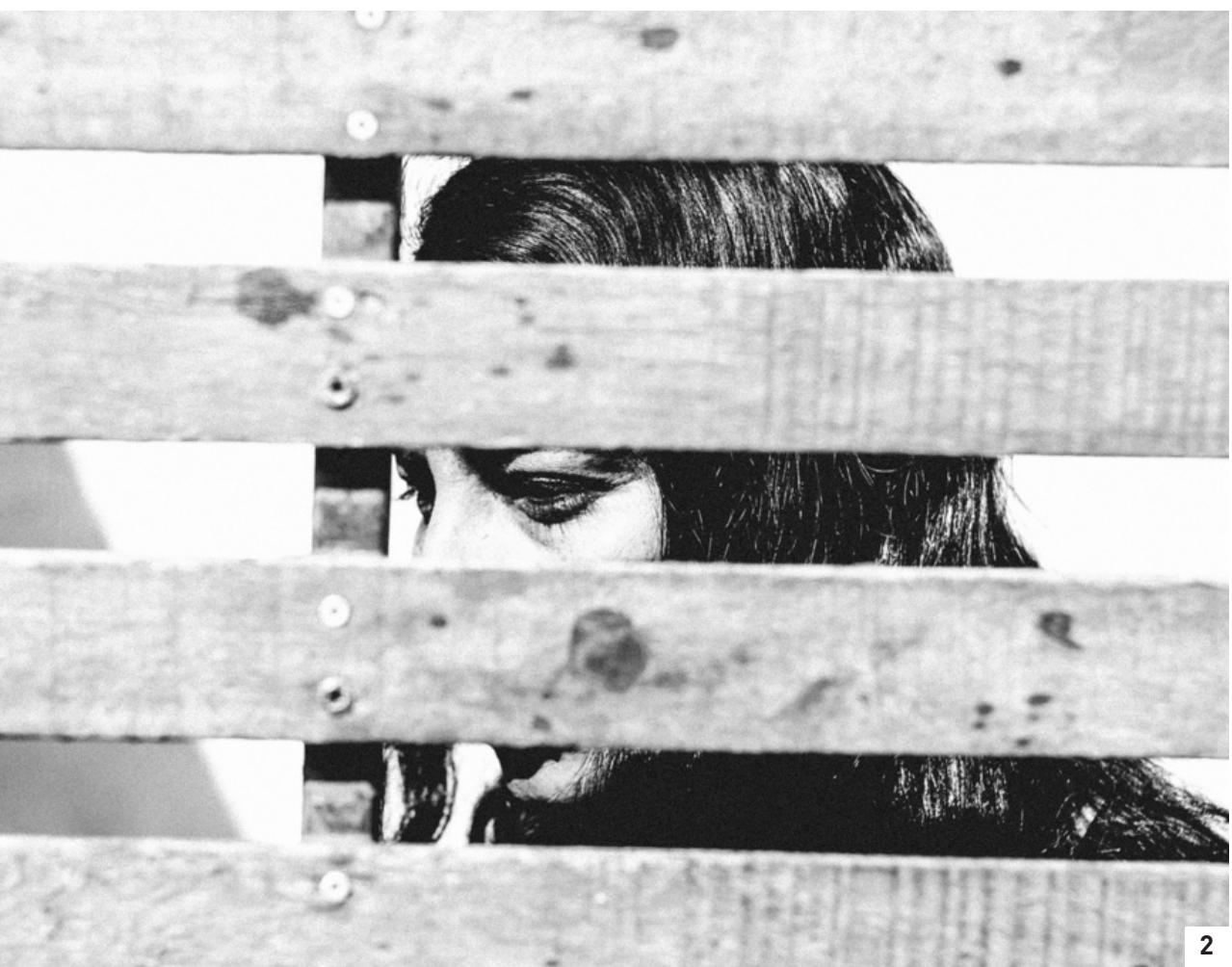

imágenes, apelamos a encontrar de qué manera los sentidos connotados funcionaban bajo figuras retóricas. En este caso, la mayoría de ellas utilizan la analogía y la metáfora para referirse al ciclo de la violencia de género, enfatizando especialmente la representación de la violencia física. Por último, discutimos y tensionamos nuestras apreciaciones preliminares con el fotógrafo y autor, entablando así un diálogo de ida y vuelta entre las imágenes, su contexto de producción, las intenciones del artista sobre su trabajo, alimentando un análisis que reconoce, también, las condiciones de producción.

El fotolibro está compuesto por 56 fotografías en blanco y negro. Ante un corpus visual extenso para los fines del presente manuscrito, las imágenes incluidas como ejemplos en este artículo son aquellas que, con mayor claridad, ilustran las retóricas que representan las violencias sexistas. Las imágenes en sí son estereotipos de alto impacto y recurren a ciertos clichés visuales que, usualmente, circulan en diferentes textualidades mediáticas que abordan la violencia de género, tales como cadenas y candados para ilustrar la privación de libertad, el encierro o la condena (Fotografía 1). Se constata, también, la inclusión explícita de rejas y barrotes para simbolizar situaciones de aislamiento forzado (Fotografía

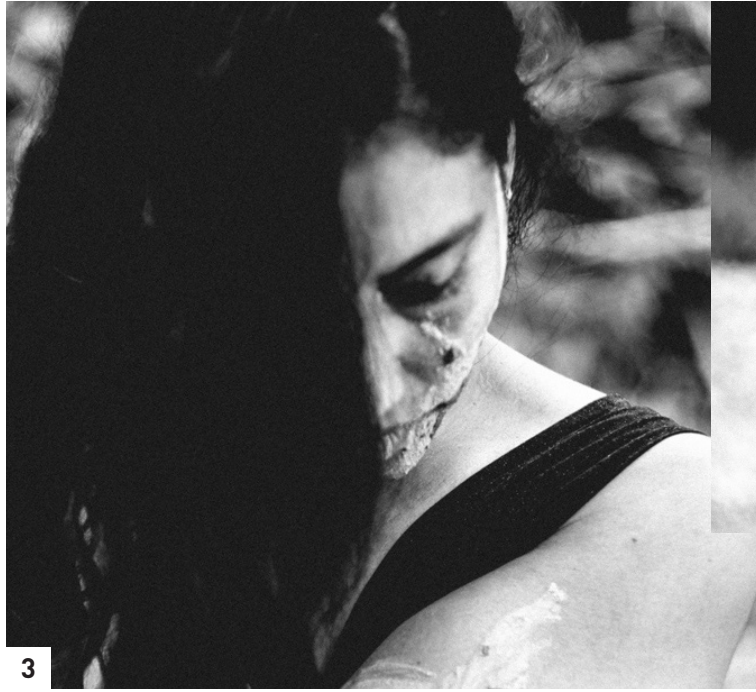

Fotografía 2. Sin título.

Fuente: IÑIGUEZ, G. Siete Vidas. Sobrevivir a la violencia machista. Salta: El Pentaprisma, 2018, p. 53.

Fotografía 3. "Vivía en un estado de completo sometimiento físico y mental". Fuente: INIGUEZ, G. Siete Vidas. Sobrevivir a la violencia machista. Salta: El Pentaprisma, 2018, p.43.

2). Manos de barro marcadas sobre diferentes partes del cuerpo como vestigio de una vejación, de un dolor punzante, una marca imborrable (Fotografía 3). Rostros desdibujados mediante el uso explícito de un fuera de foco como analogía a la invisibilidad en la que la sociedad ubica a las víctimas (Fotografía 4). Mordazas de carne y hueso que silencian los relatos de la crueldad patriarcal (Fotografía 5). Cuerpos en posición fetal, solos, sentados en entornos oscuros, rendidos, abatidos, vencidos por el peso de una mano en alto que descarga toda la culpa en su condición de género (Fotografía 6 y7).

La centralidad del rol de las manos no es una elección azarosa: Nuestra cultura reserva un lugar especial para ellas. En nuestra cultura de influencia judeocristiana es la mano de Dios la que crea, que le otorga a Adán la vida a su imagen y semejanza; es la mano la que sana y resucita a los muertos; etimológicamente, proviene de la palabra en latín manus que simbolizaba en la Antigua Roma la autoridad, el poder y la fuerza del pater familiae, es decir, de los varones y ciudadanos dueños de la propiedad privada (incluidas esclavos, niños y mujeres). 

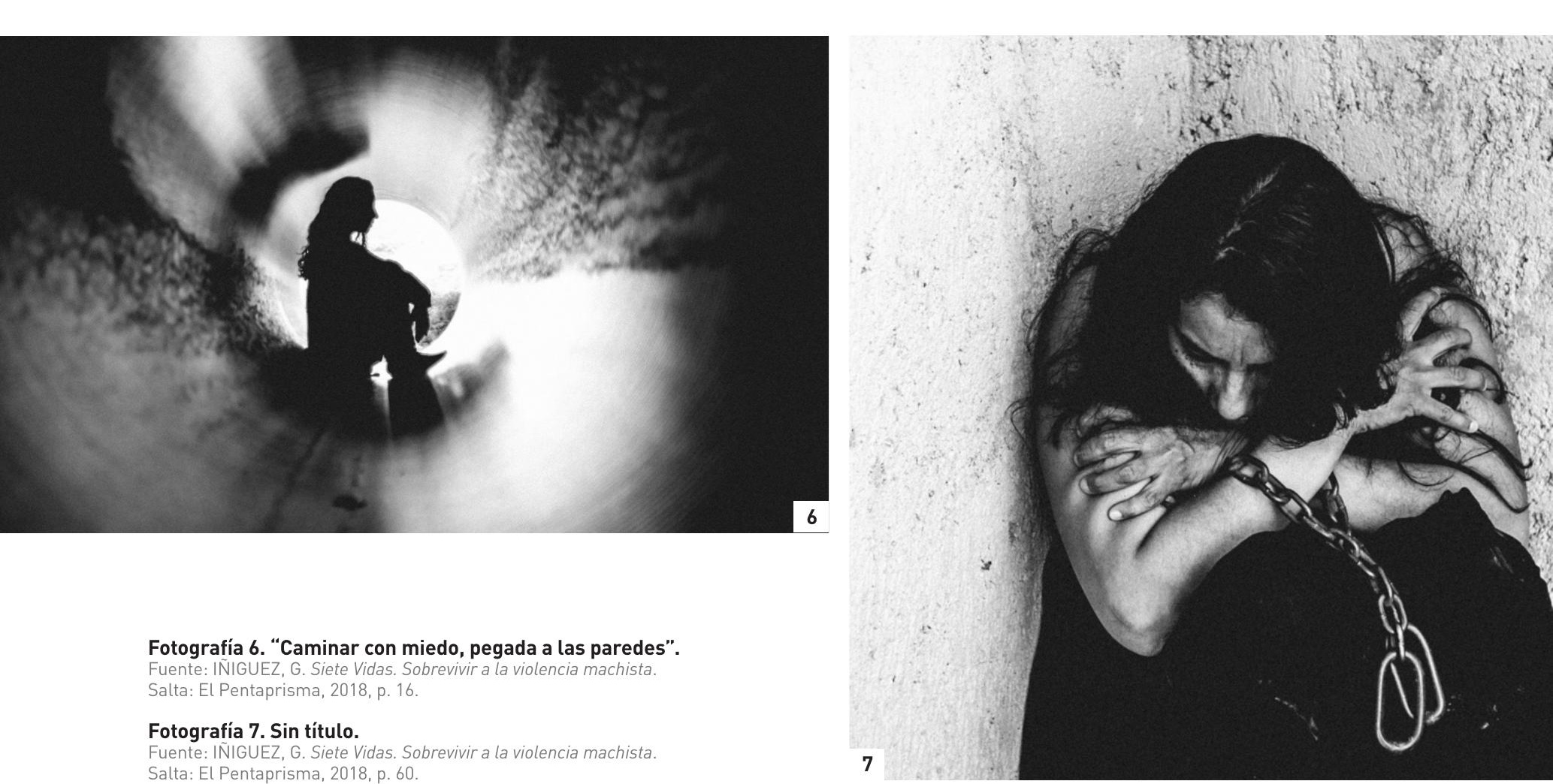

Fotografía 6. "Caminar con miedo, pegada a las paredes". Fuente: IÑIGUEZ, G. Siete Vidas. Sobrevivir a la violencia machista. Salta: El Pentaprisma, 2018, p. 16.

Fotografía 7. Sin título.

Fuente: IÑIGUEZ, G. Siete Vidas. Sobrevivir a la violencia machista. Salta: El Pentaprisma, 2018, p. 60 de inhibición, vergüenza y culpabilización actúan como dispositivos disciplinadores que obturan la posibilidad de desandar las múltiples violencias y los estereotipos de género (Fernández-Boccardo, 2016). Por ejemplo, en el caso de la fotografía 3, el fotógrafo utilizó un fuera de foco para representar el hecho de que, aunque la sociedad no la perciba, la violencia de género está siempre al acecho, no sólo es invisible el problema sino también quienes la padecen. En el caso de la fotografía 4, el pie de foto remite a aquellos discursos que justifican la violencia identificándola como una patología, una anormalidad, una monstruosidad. Recurrir a la demencia, la monstruosidad y la anomalía para hacer inteligible la violencia de género perpetúa la naturalización y banalización del problema. Ello cancela, además, discutir sobre las violencias y las masculinidades hegemónicas como único destino posible, sobre cuyos códigos y pactos culturales se sustenta y perpetúa el patriarcado (Segato, 2003).

Las historias de Siete Vidas intentan vencer el miedo, denunciando la cultura femicida (Pineda, 2019) y de la violación. En ese contexto, el acoso sexual en ámbitos laborales y el acoso callejero emergen como lugares comunes en las historias de estas mujeres. El texto del pie de foto "caminar con miedo, pegada a las paredes" (Fotografía 6) lo intenta, así, visibilizar.

\section{Del dolor al deseo: reinventar el cuerpo violentado}

Nuestra premisa inicial sostenía que el proyecto fotográfico podría contener modos no estereotipados de representar visualmente la violencia de género. Estas expectativas se desprendían principalmente de las anticipaciones de sentido contenidas en el título del fotolibro, el cual expresa que los relatos allí contenidos eran historias de mujeres sobrevivientes de la violencia sexista. En este sentido, enfatizan los relatos que hoy tienen escasa o nula presencia en los medios de comunicación que, por el contrario, privilegian encuadres de horror y muerte sobre la temática.

A raíz del proceso de lectura y análisis visual del ensayo Siete Vidas, podemos afirmar que éste reproduce y legitima los marcos visuales hegemónicos en torno a la representación de las violencias sexistas pues construye estereotipos que exploran y acentúan sólo la manifestación física del acto violento como una totalidad abarcadora, tal como observamos en otras textualidades mediáticas, como discursos publicitarios y campañas de bien 
público y/o de prevención de las violencias. En este sentido, visualmente participan de lo que Barthes denomina el studium, en tanto que hay en dichas fotografías elementos que podrían ser identificados, leídos por cualquier espectador y que se relacionan con los modos epocales y culturales del ver, por lo tanto, son la parte visible de la ideología. Del mismo modo, son esos elementos lo que permiten que dichas imágenes sean comprendidas como la expresión de la violencia de género y no como pertenecientes a escenas de otra índole.

La representación por metonimia y analogía que realiza el fotógrafo respecto a la violencia y su intención de reflejar los relatos de las siete mujeres que inspiraron la realización del proyecto, lo conduce a un error común. Señala Reyero (2015) que “la puesta en imágenes de algún aspecto de la realidad del otro, tiende a reducirlo a ciertos estándares iconográficos de representación sino que también alimenta todo tipo de fantasías relacionadas con su desconocimiento" (p.10). Iñiguez menciona en varios pasajes del libro, así como en la entrevista realizada para este trabajo, que Siete Vidas es un acto de justicia con las imágenes de mujeres abatidas y rotas que circulan en los medios de comunicación. Sin embargo, en su intento de "reparar" una situación de vulnerabilidad, “la cámara actúa como legitimadora de un rol de autoridad (...) la fotografía se vuelve así valorada (...) desde su supuesta capacidad metonímica de evidenciar parte de la realidad" (Reyero, 2015, p.10). El despegue estético para representar escenas de violencia cobra más importancia que el hecho de narrar desde otro lugar $y$, desafortunadamente, cae en lugares que pretendía desandar.

Las imágenes logradas en el artículo analizado son, en cierta medida, "objetos de inatención", paradojas visuales, que obturan debates más profundos y necesarios sobre el tema, en especial, sobre la relevancia de la violencia simbólica como mecanismo subsidiario de la reproducción de desigualdades y la dificultad ante la cual nos coloca su representación y régimen visual. En todo caso, dicha dificultad viene atada a las características propias del dispositivo fotográfico y su condición como signo; su carácter icónico-indicial condiciona las posibilidades de representar las huellas y marcas del ejercicio del poder simbólico sobre la psiquis de las víctimas. En este sentido, otra barrera observada se relaciona con la poca relevancia que, a nivel social, se le otorga a este de tipo de violencia: se la banaliza, se la cuestiona sin comprender que, tal como señala Bourdieu, sobre ella se apoya la reproducción de desigualdades. En palabras de Femenías (2013), es aquella que "aísla, segrega, recluye, genera marginalidades, divide, condena y hasta aniquila o extermina, sino directamente al menos indirectamente, en la medida que justifica o legitima la violencia física" (p.101).

Los problemas señalados no son exclusivos del proyecto ni de su autor, sino que forman parte de los debates actuales en torno a las políticas de representación y la preocupación por encontrar visibilidades que punzen, ardan y se quemen, agitando las aguas calmas del morbo imperante en los productos culturales y que atenten contra los intentos cotidianos de despolitizar lo personal. La incapacidad de pensar otros modos de visibilidad para las violencias de género es directamente proporcional a la dificultad que representa imaginar un mundo libre de violencias para la diversidad de los géneros. Las imágenes del horror nos empujan a reconfigurar continuamente los límites de lo tolerable, la anestesia visual que generan dichos estereotipos visuales alimentan el silencio de la mirada que es, a su vez, el silencio de las muertas y de las sobrevivientes a las cuales se les niega la posibilidad de contar su historia, de existir como sujetas por fuera del lugar fatídico de la víctima.

¿Qué horizontes nuevos se vislumbran para las mujeres, franqueando el miedo?, ¿es posible sobrevivir a la violencia de género?, ¿cuáles son los mapas de la esperanza de los que nadie habla?, ¿es la libertad un imposible? El hartazgo generalizado contra los relatos del horror demuestra la urgencia de contar a viva voz las otras historias, aquellas que dan cuenta de que hay vida posible por fuera del círculo de la violencia. En este sentido, Siete Vidas es un intento de justicia contra el olvido y la indiferencia generalizada socialmente.

Los retratos y las historias de estas siete salteñas - Macarena, Luisina, Magalí, Rocío, Fernanda, Jimena y Guadalupe-, son un ejemplo de que hay vida después de la violencia porque es posible no solo estar vivas, sino también libres, gozosas y deseantes (Fotografía 8 ).

Didi-Huberman sostiene que el ejercicio de imaginar pese a todo reclama del fotógrafo una toma de 
conciencia de que deberá hacerle frente a "la difícil ética de la imagen: ni la invisible por excelencia (pereza del esteta), ni el ícono del horror (pereza del creyente), ni el simple documento (pereza del sabio). Una simple imagen: inadecuada pero necesaria, inexacta pero verdadera" (2004, p. 67). Y es aquí en donde el trabajo de Iñiguez destaca porque, al menos y a diferencia de muchos que prefieren no mirar, el fotógrafo hace el intento no sólo de imaginar y pensar en los relatos y de figurarlos, sino que avanza en representarlos y hasta se propone, conscientemente, hacerlo desde otros lugares no explorados. Algunas imágenes materializan su pretensión original y, en otras, cae en clichés vi-
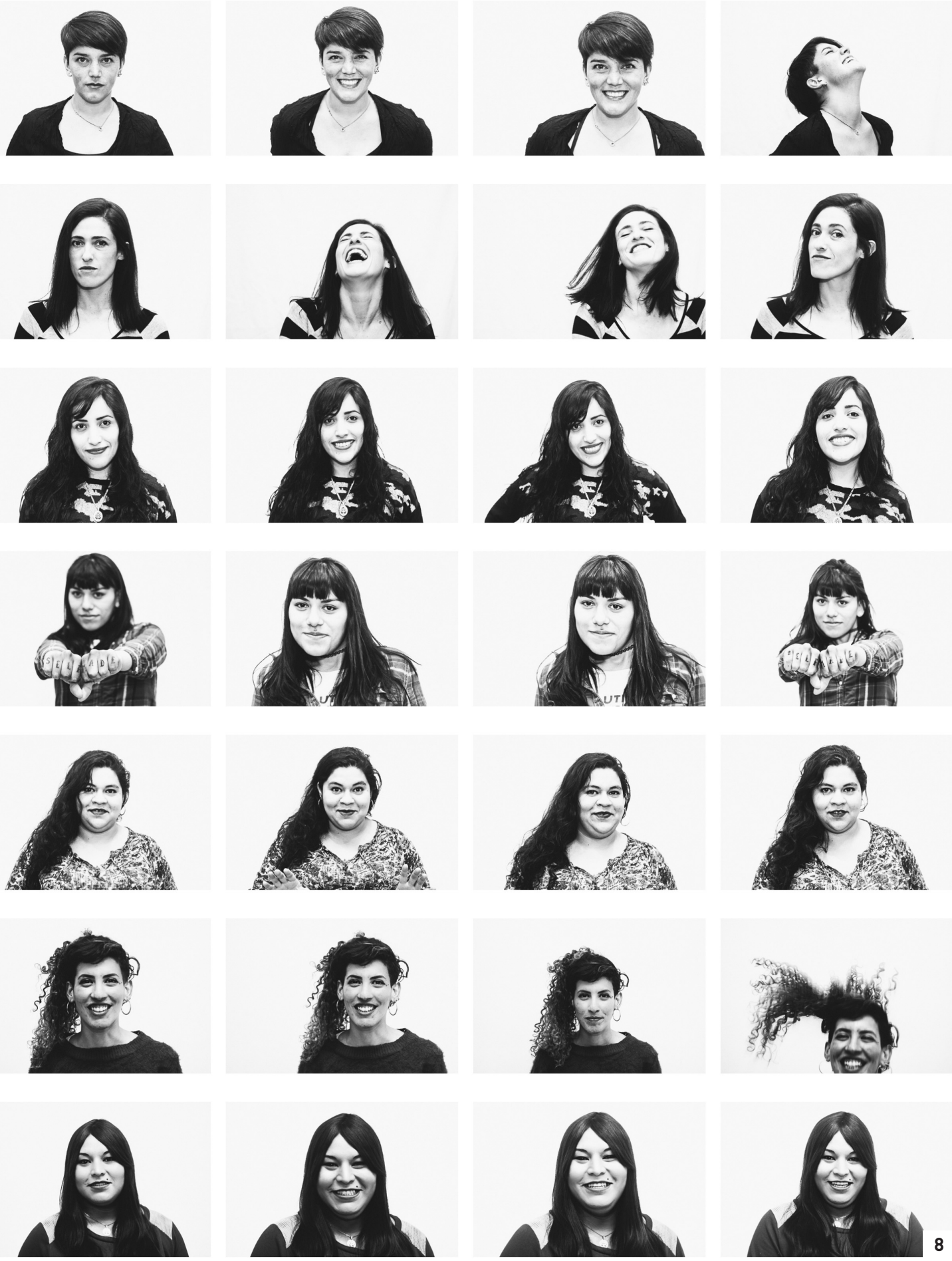

Fotografía 8. Epílogo. Fuente: IÑIGUEZ, G. Siete Vidas. Sobrevivir a la violencia machista. Salta: El Pentaprisma, 2018, p. 72. 
suales, en aquellas formas estereotipadas que la cultura ha habilitado y legitimado para visibilizar y hablar de las violencias: "reconozco que las imágenes caen indefectiblemente en ciertos lugares comunes, mostrar el miedo, manos con cadenas, la persecución, etc. y también entiendo que no hubiera podido hacerlas de otra forma", sostiene el fotógrafo (Iñiguez, comunicación personal, 2019).

Pese a esto, el intento de representar lo inimaginable, esos pequeños fragmentos de verdad que intentan pensar y entender la violencia contra las mujeres desde otro lugar, es loable. Incomodan, desestabilizan, nos interpelan políticamente, nos cuestionan, nos punzan ahí en donde todos callamos, nos arden los ojos en fuegos de diferentes intensidades; los relatos se multiplican, las frases resuenan, se hacen eco y movilizan lo íntimo, se vuelven grito multitudinario, vencen al silencio y nos arrancan del lugar de pasividad e inacción reservado para los cómplices. La urgencia nos une, nos convertimos en ola, ya somos visibles. En una sociedad cómplice, donde nuestras vidas nada valen, es imperioso, parafraseando a Didi-Huberman, vivir pese a todo.

\section{Notas}

1. Gastón Iñiguez nació en Buenos Aires el 18 de junio de 1983, tiene 37 años y es fotógrafo, fotoperiodista y docente de técnicas de fotografía en la carrera de $\mathrm{Di}$ seño Gráfico en el Terciario Provincial de Bellas Artes de la ciudad de Salta. Estudió fotografía en el Instituto.

2. Semanario impreso de la provincia de Salta, Argentina.

3. Artista y profesora de danza salteña. Mujer sobreviviente de violencia de género.

4. El río la Caldera y la localidad que se emplaza a sus orillas de nombre homónimo, quedan ubicados al norte de la ciudad de Salta capital, Argentina, sobre la ruta nacional $n^{\circ} 9$.

5. El cuerpo de Daniela Guantay fue encontrado en el río Mojotoro; el de Paola Alvarez, a orillas del río La Caldera; el de Camila Rodríguez, en un cañaveral cerca de un curso de agua en Orán, y, finalmente, el de Cintia Carmen Tapia apareció a orillas del dique Cabra Corral.

\section{Referencias}

AAVV. (2017). Proyecto NUM. Recuperemos la imaginación para cambiar la historia. Buenos Aires: Mandrágora.

Arancibia, V. y Cebrelli, A. (2005). Representaciones sociales. Modos de decir y de hacer. Salta: Cepiha.

Aumont, J. (1992). La imagen. Buenos Aires: Paidós Comunicación.

Barrios, C. (2018). Experiencias visuales de umbral: el 'Gauchito' fotogénico y diferencial desde capturas en desplazamiento. Cuadernos de Humanidades, 29, 99-122.

Barthes, R (1984). El susurro del lenguaje. Más allá de la palabra y de la escritura. Barcelona: Paidós.

Barthes, R. (1982). Lo obvio y lo obtuso. Imágenes, gestos y voces. Barcelona: Paidós.

Barthes, R. (1989). La cámara lúcida. Notas sobre la fotografía. Barcelona: Paidós.

Berger, J. (2016). Modos de ver. Barcelona: Gustavo Gilli.

Berlanga Gayón, M. (2014). El color del feminicidio: de los asesinatos de mujeres a la violencia generalizada. El Cotidiano, 184, 41-46. 
Bourdieu, P. (2000). La dominación masculina. Barcelona: Anagrama.

Butler, J. (2010). Marcos de guerra. Las vidas lloradas. Buenos Aires: Paidós.

Crenshaw, K. (2012). "Cartografiando los márgenes. Interseccionalidad, políticas identitarias y violencia contra las mujeres de color" (pp. 87-122). En Platero, R. (Lucas) [Ed.]. Intersecciones: cuerpo y sexualidades en la encrucijada. Temas contemporáneos. Madrid: Ed. Bellaterra.

Deharbe, D (2019). Entrevista a Gastón Iñiguez sobre Siete Vidas. Comunicación personal.

Deharbe, D. y Zurita, I. (2019). La (in)visibilidad de las mujeres trans en la televisión local. Disputa representacional en torno al 8M en Salta. Polémicas Feministas, (3).

Didi-Huberman, G. (2004). Imágenes pese a todo. Memoria visual del Holocausto. Barcelona: Paidós.

Femenías, M. L. (2013). Violencias cotidianas en la vida de las mujeres. Rosario: Prohistoria.

Fernández Boccardo, M. (2016). Mujeres que callan. Violencias de género y efectos en la subjetividad femenina. Rosario: Ed. Entre ideas.

Fernández, A. M. (1993). La mujer de la ilusión. Pactos y contratos entre hombres y mujeres. Buenos Aires: Paidós.

Guasch, A. M (2006). Los estudios visuales. Un estado de la cuestión. Revista Arte e Investigación, 10 (5), 10-14.

Iñiguez, G. (2018). Siete Vidas. Sobrevivir a la violencia machista. Vaqueros, Salta: El Pentaprisma.

Joly, M. (2012). Introducción al análisis de la imagen. Buenos Aires: La Marca Editora.

Lockett Destri, M. (2014). Proyecto Enfocadas: una experiencia grupal realizada con mujeres que sufrieron en el pasado violencia por parte de sus parejas, utilizando la fotografía y la narración como herramienta terapéutica. Arteterapia. Papeles de arteterapia y educación artística para la inclusión social, 9, 225-246. https://doi. org/10.5209/rev_ARTE.2014.v9.47493

López-Ruiz, D. y López-Martínez, M. D. (2019): Fototerapia como narrativa visual: aplicación en violencia de género. Estudios sobre el Mensaje Periodístico, 25, (1), 317-334. https://doi.org/10.5209/ESMP.63731

Miguel Saenz de Urabain, A. (2015). ¿Puede la fotografía mostrar lo inimaginable? El debate en torno a la representación de la Shoah. Fotocinema. Revista Científica de Cine y Fotografía, 10, 233-262. https://doi.org/10.24310/Fotocinema.2015.v0i10.5986

Newhall, B. (2002). Historia de la fotografía desde 1839 al presente. Barcelona: Editorial Gustavo Gili.

Olayo, V. y Herrera, M. (2014). Fotografía y Violencia: la memoria actuante de las imágenes. Cuadernos de Música, Artes Visuales y Artes Escénicas, Colombia, 9 (2), 89-106. DOI:10.11144/Javeriana.mavae9-2.fvma 
Pineda, E. (2019). Cultura femicida. El riesgo de ser mujer en América Latina. Buenos Aires: Prometeo.

Reguillo, R. (2008). Saber y poder de representación. La(s) disputa(s) por el espacio interpretativo. Comunicación y Sociedad, 9, 11-33.

Reyero, A. (2015). Imagen, texto y artefacto. La fotografía etnográfica del Gran Chaco argentino en publicaciones impresas contemporáneas. Artelogie, Recherche sur les arts, le patrimonie et la littérature de l'Amerique latine, (7). https://doi.org/10.4000/ artelogie.1139

Segato, R (2016). La guerra contra las mujeres. Madrid: Traficantes de Sueños.

Segato, R. (2003). Las estructuras elementales de la violencia. Ensayos sobre género entre la antropología, el psicoanálisis y los derechos humanos. Bernal: Universidad Nacional de Quilmes.

Silva Santisteban, R. (2008). El factor asco. Basurización simbólica y discursos autoritarios en el Perú contemporáneo. Lima: PUCP.

Sontang, S. (2004). Ante el dolor de los demás. España: Suma de Letras.

Vásquez Escalona, A. (2011). El ensayo fotográfico, otra manera de narrar. Quórum Académico, 8 (16), 301-314.

Vilches, L. (1993) Teoría de la imagen periodística. Barcelona: Paidós.

- Sobre la autora:

Diana Deharbe es Becaria doctoral del Consejo Nacional de Investigaciones Científicas y Técnicas, Argentina. Doctoranda en Comunicación Social (Universidad Nacional de Rosario). Licenciada en Comunicación Social (Universidad Nacional de Entre Ríos).

\section{- ¿Cómo citar?}

Deharbe, D. (2020). La representación fotográfica del círculo de la violencia de género en Salta, Argentina. Comunicación y Medios, (42), 56-69. https://doi.org/10.5354/07191529.2020 .58618 